\title{
Determinants of Hand Hygiene Practice at Critical Times among Food Handlers in Educational Institutions of the Sagnarigu Municipality of Ghana: A Cross-Sectional Study
}

\author{
Kingsley E. Amegah \\ Hohoe Municipal Hospital \\ Henry 0. Addo \\ University of Ghana \\ Mary E. Ashinyo \\ Ghana Health service \\ Loveland Fiagbe \\ University of Cape Coast
}

\section{Serene Akpanya}

Hohoe Municipal Hospital

\section{Samuel K. Akoriyea}

Ghana Health Service

S. Dajaan Dubik ( $\nabla$ stephendubik@gmail.com )

University for Development Studies https://orcid.org/0000-0001-9833-2676

\section{Research Article}

Keywords: Food handling, hand hygiene, food safety, educational institutions, Ghana

Posted Date: October 12th, 2020

DOI: https://doi.org/10.21203/rs.3.rs-47681/v2

License: (c) (i) This work is licensed under a Creative Commons Attribution 4.0 International License.

Read Full License

Version of Record: A version of this preprint was published at Environmental Health Insights on January 1st, 2020. See the published version at https://doi.org/10.1177/1178630220960418. 
Determinants of Hand Hygiene Practice at Critical Times among Food Handlers in Educational Institutions of the Sagnarigu Municipality of Ghana: A Cross-Sectional Study

\author{
Kingsley E Amegah'1 (i), Henry O Addo² (iD, Mary E Ashinyo³, \\ Loveland Fiagbe ${ }^{4}$, Serene Akpanya ${ }^{5}$, Samuel K Akoriyea ${ }^{3}$ \\ and S Dajan Dubik' ${ }^{\text {iD }}$
}

${ }^{1}$ Department of Health Information, Hohoe Municipal Hospital, Hohoe, Ghana. ${ }^{2}$ Department of Animal Biology and Conservation Science, University of Ghana, Ghana. ${ }^{3}$ Institutional Care Division, Ghana Health Service Headquarters, Accra, Ghana. ${ }^{4}$ Department of Marketing and Supply Chain Management, University of Cape Coast, Ghana. ${ }^{5}$ Department of Health

Administration, Hohoe Municipal Hospital, Hohoe, Ghana, Ghana. ${ }^{6}$ Department of Nutritional Sciences, School of Allied Health Sciences, University for Development Studies, Tamale, Ghana.
Environmental Health Insights

Volume 14: 1-10

(C) The Author(s) 2020

Article reuse guidelines:

sagepub.com/journals-permissions

DOI: $10.1177 / 1178630220960418$

(S)AGE

\begin{abstract}
INTRODUCTION: Food handlers' hands serve as a vehicle for potential foodborne pathogenic contamination which constitutes a public health risk. In Ghana, there are always constant reports of outbreaks of foodborne diseases in schools. However, determinants of hand hygiene practice among educational institutions food handlers are little known. The study, therefore, aimed to assess the determinants of hand hygiene practice at critical times among educational institutions' food handlers in the Sagnarigu Municipality of Ghana.

METHODS: This was a cross-sectional survey among educational institutions food handlers in the Sagnarigu Municipality. Two hundred and six food handlers were selected through convenience sampling in the educational institutions. At the same time, structured questions that were developed from previous studies were used to assess food handlers' hand hygiene practice at critical times. Data were analyzed using descriptive statistics, bivariate and multivariate logistic regression models. All variables with their respective confidence intervals (95\%) and adjusted odds ratios were declared significant at $P$-values less than .05 .
\end{abstract}

RESULTS: Hand hygiene practice at critical times among the food handlers were relatively good at a rating of $66.0 \%$ (95\% Cl: $59.1,72.5 \%)$ Good hand hygiene practice at critical times was less likely among food handlers with no food safety training (AOR 0.04; 95\% Cl: 0.00, 0.41) and food handlers who had insufficient knowledge of hand hygiene (AOR 0.06; 95\% $\mathrm{Cl} 0.01,0.25$ ). Good hygiene practice at critical times was $99 \%$ lower in food handlers with a negative attitude as compared to food handlers with positive attitudes towards hand hygiene at critical times (AOR 0.01; 95\% Cl 0.00, 0.07). Only 17.0\% of the food handlers demonstrated proper handwashing techniques, whereas a good number $(85.4 \%)$ of the food handlers did not wash their hands after touching money.

CONCLUSION: Good hand hygiene practice at critical times was relatively good. Food safety training, knowledge of hand hygiene and attitudes towards hand hygiene were independent predictors of hand hygiene practice at critical times. Concerned stakeholders and organizations should focus on WASH interventions that seek to improve educational institutions food handlers' knowledge and attitudes towards hand hygiene, coupled with training on food safety.

KEYWORDS: Food handling, hand hygiene, food safety, educational institutions, Ghana

RECEIVED: August 18, 2020. ACCEPTED: August 31, 2020

TYPE: Original Research

FUNDING: The author(s) received no financial support for the research, authorship, and/or publication of this article.
DECLARATION OF CONFLICTING INTERESTS: The author(s) declared no potential conflicts of interest with respect to the research, authorship, and/or publication of this article.

CORRESPONDING AUTHOR: S Dajaan Dubik, Department of Nutritional Sciences, School of Allied Health Sciences, University for Development Studies, Tamale, Ghana. Emails: stephendubik@gmail.com; sdajaan@uds.edu.gh

\section{Introduction}

Foodborne diseases constitute a public health threat and negatively affect the social and economic development of global economies. For example, millions of foodborne illnesses occurred in 2010, which translated to approximately 420000 deaths across the globe. ${ }^{1}$ In developing countries, diseases, disability and deaths resulting from unsafe food lead to a productivity loss of billions of US dollars. ${ }^{2}$ Africa and South Asia bear the most significant burden of foodborne diseases. ${ }^{3}$ All populations are at risk of foodborne infections, but under 5 children carry the enormous weight of morbidity and mortality resulting from foodborne illnesses. ${ }^{3}$ The situation in Ghana is not different. There are approximately 420000 reported cases of foodborne diseases every year with an estimated annual death of 65000 in Ghana; this results in a monetary loss of US\$69 million to the already overburdened Ghanaian economy every year. ${ }^{4}$ Indeed, studies examining the microbial quality of ready-to-eat (RTE) foods in Ghana have isolated Enterobacter spp., Escherichia spp., Staphylococcus spp., Pseudomonas spp., Citrobacter spp. and Klebsiella spp..$^{5-7}$ 
Infectious disease agents such as diarrheal disease agents (norovirus and Campylobacter spp.) are the persistent cause of foodborne diseases. ${ }^{1}$ However, chemical contaminants are also implicated in foodborne diseases; for instance, infant formula contamination with melamine in China resulted in 294000 cases of illness with at least 6 deaths. ${ }^{8}$ Causes of foodborne disease whether infectious agents or chemical contaminants are due to unsafe food, which may be caused by improper handling. ${ }^{9}$ Furthermore, in developing countries, foodborne diseases are prominent due to poor handling, inadequate food safety legislation, weak regulatory monitoring capacities and insufficient education of food handlers on food safety. ${ }^{10,11}$

Food handlers play a critical role in ensuring food safety and the prevention of diseases resulting from RTE foods. However, poor personal hygiene practices, including handwashing by infected food handlers, can transmit foodborne disease-causing agents to food products. ${ }^{12}$ Moreover, food handlers' hands are commonly contaminated with foodborne pathogens, ${ }^{13-15}$ and this may be a vehicle in spreading foodborne disease agents through cross-contamination of food to immediate consumers. ${ }^{14,16}$ The hands of the food handler could be the principal source of food contamination. ${ }^{17}$ Hence, microbial contamination of food from food handlers' contaminated hands is, therefore, a public health problem. ${ }^{18}$

Proper hand hygiene is the act of wetting hands with clean running water, followed by the vigorous rubbing of lathered hands together for at least 20 seconds, rinsing them under clean running water and drying the washed hands with a clean tissue, towel or air drier. ${ }^{19}$ Proper hand hygiene is highly effective in limiting the transmission of foodborne diseases and a range of other disease conditions. ${ }^{20}$ The World Health Organization's 5 keys to safer foods recommend essential hand hygiene practices for food handlers often coined 'hand hygiene at critical times' to ensure proper hand hygiene in food handling. Hand hygiene at critical times includes washing hands with soap and water before handling food, before/after eating, after going to the toilet, after handling raw food, after handling garbage/waste, after changing the baby diaper or cleaning the baby bottom, after sneezing, after handling money, after touching animals and after touching body parts. These hand hygiene practices are critical in ensuring food safety and in the prevention of foodborne diseases in the food business. ${ }^{21}$

In Ghana, there is always a constant report of the outbreak of foodborne diseases in educational institutions. ${ }^{22-25}$ For instance, Ameme et $\mathrm{al}^{22}$ and Opare et $\mathrm{al}^{23}$ reported the outbreak of gastroenteritis in two senior high schools in which the consumption of contaminated food and water were implicated. Rice and groundnut soup, stew, 'waakye' and 'shitor', 'banku', 'kenkey', macroni, salad and water are commonly contaminated foods in Ghanaian schools. 6,23,26,27

Food handlers are considered as a very important source of foodborne diseases in educational institutions in Ghana. ${ }^{23,26,6}$ Indeed, the hands of food handlers are known as the principal source of food contamination. ${ }^{17}$ Additionally, the simultaneous handling of RTE food and money in the food business is of public health concern because previous studies suggest the contamination of currency notes with Escherichia spp., Staphylococcus spp. and Salmonella spp. in Ghana. ${ }^{28,29}$ However, several studies have only examined food hygiene practices of street food handlers ${ }^{30-33}$ and educational institutions' food handlers in Ghana ${ }^{11,34-36}$ with limited focus on hand hygiene practices of food handlers in educational institutions. Studies done in Ghana suggest that food handlers have poor hand hygiene practice. ${ }^{17,33}$ Sagnarigu Municipality has many educational institutions with many food handlers, yet the determinants of food handlers' hand hygiene practices in educational institutions are little known. The current study, therefore, aims to assess the determinants of hand hygiene practices at critical times among educational institutions food handlers in the Sagnarigu Municipality of Ghana.

\section{Methods}

Study design and area

A descriptive cross-sectional study was employed to assess the determinants of hand hygiene practices at critical times among educational institutions food handlers in the Sagnarigu Municipality of Northern Ghana. The Sagnarigu Municipality was carved out of Tamale Metropolis in 2012. The municipality has a population of 148099 with males constituting approximately $50.6 \%$ of the people. The economy of the municipality is mainly agriculture and commerce-based. ${ }^{37}$ The municipality has a total of 122 primary schools, 57 junior high schools and 4 senior high schools. The municipality is home to several tertiary institutions such as Tamale Technical University, Tamale College of Education, Bagabaga College of Education, Tamale School of Hygiene, Tamale Community Health Nursing, Workers College and Graduate School of the University for Development Studies. ${ }^{38}$

\section{Sample size and sampling}

The sample size was determined using the Cochran formula ${ }^{39}$ with the following parameters: $\mathrm{N}=$ the desired sample size, $\mathrm{Z}=1.96$ (the critical value of confidence level at 95\%), $P=82 \%$ (estimated magnitude of hand hygiene practices after toilet in Ghana), ${ }^{17} \mathrm{~d}=0.05$ (level of precision). $\mathrm{N}=\frac{z^{2} \times p(1-p)}{d^{2}}$, $\mathrm{N}=\frac{(1.96) 2 \times 0.82(1-0.82)}{(0.05) 2}=228$, bearing in mind, a $10 \%$ non -response rate, the final sample size was approximately 251. However, the calculated sample size could not be reached due to the limited number of food handlers in the educational institutions. Through convenience sampling, the researchers approached the food handlers in the educational institutions and invited them to participate in the study. This means that a total of 302 readily available food handlers across the educational institutions were invited to participate in the study at the 
time of our visit to the schools. All food handlers who agreed to participate in the study were therefore interviewed, giving rise to the sample size of 206 food handlers.

\section{Inclusion and exclusion criteria}

The study was limited to only stationary food handlers while mobile food handlers and government-employed institutional food handlers for boarding schools were excluded from the study. Educational institutions that were on school break were eliminated from the survey since the food handlers only report to work on the resumption of academic work for students. The participating institutions were basic, senior high and tertiary level schools.

At the tertiary level, only Tamale Technical University and Graduate School of the University for Development Studies were in session, making them the only tertiary institutions that qualified for their food handlers to participate in the study. However, the Graduate School of the University for Development Studies was excluded because there were no stationery food handlers on the campus of the school.

\section{Data collection}

The tool for the data collection was adapted from two similar published studies that were conducted in Ethiopia and Malaysia ${ }^{40,41}$ and modified to suit food handlers. The study tool was further reviewed by a Committee on Human Research, Publication and Ethics of the Kwame Nkrumah University of Science and Technology.

The questionnaire was administered using the interviewer-assisted questionnaire administration. Two graduating students of the Higher National Diploma in hospitality and tourism management were recruited to collect the data. The data collectors were trained on the data collection tool, objectives of the study, how to select the respondents and how to ensure confidentiality and ethics in the field. The data collection process was supervised by the principal investigator. Each questionnaire was reviewed for completeness, quality and consistency on each day of the data collection period. The questionnaire consisted of 5 sections: Section A, sociodemographic information and training on hand hygiene (18 questions); Section B, knowledge about hand hygiene at critical times (32 items); Section $\mathrm{C}$, hand hygiene attitudes (18 statements); Section $\mathrm{D}$, hand hygiene practice at critical times (14 questions); and Section E, observation checklist (11 items).

\section{Study variables}

Outcome variables. The two primary outcome variables were good hand hygiene and poor hand hygiene practice at critical times. Food handlers' hand hygiene practice at critical times were measured by asking 14 practice questions that pertained to whether the food handlers always washed their hands with water and soap after sneezing and coughing, after visiting the toilet, after handling raw food such as meat, before starting to sell food, after touching body parts, before/after eating, before preparing food, before handling cooked food, after touching money, after cleaning a child's bottom, after cleaning duties, after picking something on the floor, after handling waste/garbage and after touching animals.

Independent variables. The independent variables for this study were age, marital status (married, not married), religious affiliation (Christianity, Islam, others), level of education (No formal education, basic education, secondary education, tertiary education), family size (the number of people at their household), number of years of selling food (the number of years selling food in the school), training on food safety (yes, no), handwashing education (yes, no), heard about handwashing at critical times (yes, no), the sufficiency of water for handwashing in the school (yes, no), the water source for selling food (in the school, from home, others), source of information on handwashing (health workers, television, teachers, family members, other sources), type of water source (tap water, tank storage, borehole, others), materials always used in handwashing (water only, water and soap), knowledge of hand hygiene at critical times and attitude towards hand hygiene at critical times.

Knowledge of hand bygiene: Food handlers were asked 32 knowledge items with most of the questions consisting of three responses, that is, 'yes', 'no' and 'I don't know'. The knowledge questions sought to find out whether the food handlers knew hand hygiene practices at critical times, whether they knew the importance of handwashing at critical times during food handling, whether the food handlers knew handwashing at critical times will reduce food contamination, whether they knew handwashing at critical times will reduce foodborne diseases, diseases contracted by not washing hands at critical times, whether the respondent knew dirty and long fingernails could contaminate food with a disease-causing microorganism, whether the food handler knew improper hand washing can transmit microorganisms to food, whether they knew foodborne diseases can be controlled by proper hand washing, whether they knew bacteria are found on the surfaces of human skin, raw food may contain harmful bacteria that can contaminate RTE food, whether the food handler knew it is important to wash hands after handling garbage/waste, after handling money, after sneezing and coughing on hands, before preparing food, before starting to sell food, after cleaning the child's bottom, after visiting the toilet, after handling raw food and after cleaning or sweeping the environment.

Food handlers' attitudes towards hand hygiene: To measure food handlers' attitudes towards hand hygiene practices at critical times, they were asked to indicate their level of agreement 
to 19 statements with 3 possible options: 'agree', 'disagree' and 'not sure'.

\section{Measurement of study variables}

Good hand hygiene practice: Food handlers' who scored above or equal to the mean value (11.17) of the 14 hand hygiene practice questions.

Poor hand hygiene practice: Food handlers' who scored below the mean value (11.17) of the 14 hand hygiene practice questions.

Sufficient knowledge: Food handlers' who answered correctly above or equal to the mean (29.74) of the hand hygiene knowledge questions were considered as having sufficient knowledge.

Insufficient knowledge: Food handlers' who scored below the mean (29.74) of the hand hygiene knowledge questions were considered as having insufficient knowledge.

Positive attitude: Food handlers' who scored above or equal to the mean (16.94) of the 18 hand hygiene attitude questions were considered as having a positive attitude towards hand hygiene

Negative attitude: Food handlers' who scored below the mean (16.94) of the 18 hand hygiene attitude questions were considered as having a negative attitude.

\section{Data analysis}

Data analysis was performed using STATA 14.2. Statistical significance was set at a level of $P<.05$. Descriptive statistics were first used to present respondents' sociodemographic and other WASH-related information, knowledge of hand hygiene at critical times, attitudes towards hand hygiene, hand hygiene practice at critical times, and observation of hand hygiene practices in text, tables and figures. To identify the determinants of hand hygiene practices at critical times, a logistic regression analysis was performed to determine the association between food handlers' sociodemographic information, WASH-related information, knowledge of hand hygiene, attitudes towards hand hygiene and hand hygiene practice at critical times. Variables that were significant after the bivariate logistic regression analysis were included in the multivariate logistic regression analysis to determine the strength of association using their computed crude and adjusted odds ratios and respective 95\% confidence intervals.

\section{Results}

Sociodemographic characteristics of respondents and training on hand bygiene

All (100\%) of the study participants were females. The mean age was 35.9 years, with a standard deviation of \pm 9.8 years. The minimum and maximum ages were 17 and 58 years respectively with most (30.6\%) within 31 to 40 and $41+$ year age brackets. Most (85.4\%) of the respondents were married, and the majority $(83.5 \%)$ of them were affiliated with the Islamic religion (Table 1).

Most (74.8\%) of the food handlers reported ever having some form of training on food safety, and $79.6 \%$ have ever received education on handwashing. The majority $(76.7 \%)$ of the food handlers confirmed that they had ever heard about handwashing at critical times. Most (78.6\%) of the study participants reported that they had sufficient water for handwashing in their school, and slightly over half (53.9\%) of the food handlers reported that they sourced their water for selling in the school. A large majority (92.7\%) of the food handlers reported washing their hands with soap and water (Table 1 ).

Foods sold by food handlers at the various schools. The major foods sold by the food handlers in the educational institutions were rice and beans (32.0\%), sugar-based drinks and sweets (24.4\%), yam/plantain (12.6\%) and spaghetti/noodles (9.2\%) (Figure 1).

Hand hygiene practices at critical times among educational institutions' food handlers in Sagnarigu Municipality. Food handlers' hand hygiene practices at critical times are presented in Table 2. The majority of the food handlers always washed their hands with water and soap after visiting the toilet (96.6\%), after handling raw food (88.4\%), after handling cooked food (80.6\%), and after cleaning a child's stool (89.9\%). More than half $(67.0 \%)$ of the study participants always washed their hands with water and soap after touching money.

Knowledge, attitudes and practices of educational institutions' food handlers regarding hand hygiene at critical times. As summarized in Figure 2, the prevalence of good handwashing practice at critical times among the educational institutions' food handlers was $66.0 \%$ (95\% CI: $59.1,72.5)$ whereas about $65.5 \%$ of the study participants had a positive attitude towards hand hygiene at critical times. Only 34.5\% had an insufficient level of knowledge of hand hygiene at critical times.

Determinants of hand hygiene practices at critical times among educational institutions food handlers. Bivariate regression analysis revealed an association between respondents' age, training on food safety, receiving education on handwashing, heard about hand hygiene at critical times, hand hygiene knowledge, attitude and good hand hygiene practices at critical times at $P<.05$ (Table 3). Food handlers who had no training on food safety were 95\% times less likely to have good hand hygiene practice at critical times as compared to those who had training on food safety [OR=0.05, (95\% CI: 0.02-0.12) $P<.001]$. The odds of good hand hygiene practice were lower among respondents who had insufficient knowledge of hand hygiene at critical times as compared to respondents with sufficient knowledge of hand hygiene at critical times [OR=0.01, (95\% CI: 0.00-0.04) $P<.001]$. Food handlers' with a negative attitude towards hand hygiene at critical 
Table 1. Sociodemographic variables and training on hand hygiene.

\begin{tabular}{|c|c|c|}
\hline VARIABLES & $\begin{array}{l}\text { FREQUENCY, } \\
\mathrm{N}=206\end{array}$ & $\%$ \\
\hline \multicolumn{3}{|l|}{ Age group (years) } \\
\hline$<21$ & 12 & 5.8 \\
\hline $21-30$ & 68 & 33.0 \\
\hline $31-40$ & 63 & 30.6 \\
\hline $41+$ & 63 & 30.6 \\
\hline \multicolumn{3}{|l|}{ Marital status } \\
\hline Married & 176 & 85.4 \\
\hline Not married & 24 & 11.7 \\
\hline Other & 6 & 2.9 \\
\hline \multicolumn{3}{|l|}{ Religious affiliation } \\
\hline Christianity & 34 & 16.5 \\
\hline Islam & 172 & 83.5 \\
\hline \multicolumn{3}{|l|}{ Level of education } \\
\hline No formal education & 121 & 58.7 \\
\hline Basic education & 52 & 25.2 \\
\hline Secondary education & 29 & 14.1 \\
\hline College/University education & 4 & 1.9 \\
\hline \multicolumn{3}{|l|}{ Family size } \\
\hline $2-4$ & 70 & 34.0 \\
\hline $5-7$ & 103 & 50.0 \\
\hline $8-10$ & 33 & 16.0 \\
\hline \multicolumn{3}{|l|}{ Number of years selling food } \\
\hline $1-3$ & 100 & 48.5 \\
\hline $4-6$ & 84 & 40.8 \\
\hline $7+$ & 22 & 10.7 \\
\hline \multicolumn{3}{|l|}{ Category of school selling food } \\
\hline Basic school & 156 & 75.7 \\
\hline Secondary school & 28 & 13.6 \\
\hline College/University & 22 & 10.7 \\
\hline \multicolumn{3}{|l|}{ Received training on food safety } \\
\hline No & 52 & 25.2 \\
\hline Yes & 154 & 74.8 \\
\hline \multicolumn{3}{|c|}{ Received education on handwashing } \\
\hline No & 42 & 20.4 \\
\hline Yes & 164 & 79.6 \\
\hline
\end{tabular}

(Continued)
Table 1. (Continued)

\begin{tabular}{|c|c|c|}
\hline VARIABLES & $\begin{array}{l}\text { FREQUENCY, } \\
\mathrm{N}=206\end{array}$ & $\%$ \\
\hline \multicolumn{3}{|c|}{ Heard about handwashing at critical times } \\
\hline No & 48 & 23.3 \\
\hline Yes & 158 & 76.7 \\
\hline \multicolumn{3}{|c|}{ Source of information on handwashing } \\
\hline Health worker & 99 & 48.1 \\
\hline Television/Radio & 90 & 43.7 \\
\hline Teachers & 36 & 17.5 \\
\hline Family member & 1 & 0.5 \\
\hline Other sources & 1 & 0.5 \\
\hline \multicolumn{3}{|c|}{ Sufficient water for hand washing in school } \\
\hline No & 44 & 21.4 \\
\hline Yes & 162 & 78.6 \\
\hline \multicolumn{3}{|c|}{ Source of water for selling } \\
\hline In school & 111 & 53.9 \\
\hline From home & 92 & 44.7 \\
\hline Others & 3 & 1.5 \\
\hline \multicolumn{3}{|l|}{ Type of water source } \\
\hline Tap water & 155 & 75.2 \\
\hline Storage tank & 20 & 9.7 \\
\hline Borehole & 24 & 11.7 \\
\hline Others & 7 & 3.4 \\
\hline \multicolumn{3}{|c|}{ Used soap for handwashing } \\
\hline No & 15 & 7.3 \\
\hline Yes & 191 & 92.7 \\
\hline
\end{tabular}

times were $99 \%$ times less likely to have good hand hygiene practices at crucial times as compared to respondents with positive attitude [OR=0.01, (95\% CI: 0.00-0.02) $P<0.001]$ (Table 3).

In the multivariate model, respondents' age, training on food safety, knowledge of hand hygiene and attitude towards hand hygiene remained more influential determinants of good hand hygiene practice at critical times. After adjusting for age, knowledge of hand hygiene and attitude towards hand hygiene at critical times, the estimated odds of good hand hygiene practice towards hand hygiene at critical times was 0.04 times lower among respondents who were not trained on food safety than respondents who received training on food safety $[\mathrm{AOR}=0.04$, (95\% CI: 0.00-0.41) $P=.007]$. Food handlers' with insufficient knowledge of hand hygiene at critical times were 0.06 times less likely to have good hand practice at critical times than respondents with sufficient knowledge of hand hygiene 


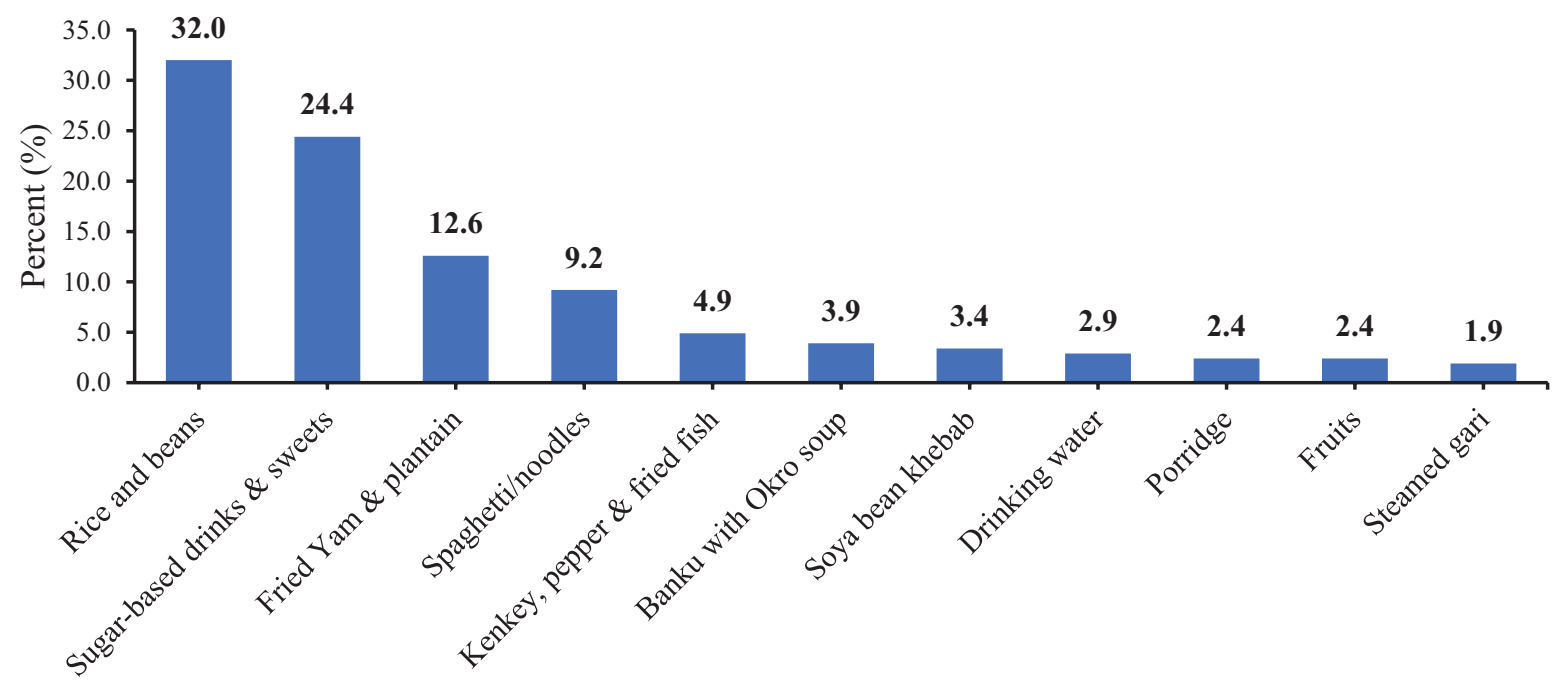

Figure 1. Foods sold by food handlers at the various schools.

Table 2. Food handlers' hand hygiene practices at critical times.

\begin{tabular}{|c|c|c|c|c|c|}
\hline \multirow[t]{2}{*}{ NO } & \multirow[t]{2}{*}{ STATEMENT } & \multicolumn{3}{|c|}{ RESPONDENTS, N (\%) } & \multirow[t]{2}{*}{$\mathrm{MEAN} \pm \mathrm{SD}$} \\
\hline & & YES & NO & $\begin{array}{l}\text { CAN'T } \\
\text { REMEMBER }\end{array}$ & \\
\hline 1 & Always wash hands with water and soap after sneezing and coughing & $150(72.2)$ & $46(22.3)$ & $10(4.9)$ & $11.17 \pm 4.07$ \\
\hline 2 & Always wash hands with water and soap after visiting the toilet & $199(96.6)$ & $6(2.9)$ & $1(0.5)$ & \\
\hline 3 & Always wash hands with water and soap after handling raw food & $182(88.4)$ & $21(10.2)$ & $3(1.5)$ & \\
\hline 4 & Always wash hands with water and soap before starting to sell food & $175(85.0)$ & $27(13.1)$ & $4(1.9)$ & \\
\hline 5 & Always wash hands with water and soap after touching your body parts & $136(66.0)$ & $62(30.1)$ & $8(3.9)$ & \\
\hline 6 & Always wash hands with water and soap before and after eating & $161(78.1)$ & $44(21.4)$ & $1(0.5)$ & \\
\hline 7 & Always wash hands with water and soap before preparing food & $161(78.1)$ & $42(20.4)$ & $3(1.5)$ & \\
\hline 8 & Always wash hands with water and soap before handling cooked food & $166(80.6)$ & $34(16.5)$ & $6(2.9)$ & \\
\hline 9 & Always wash hands with water and soap after touching money & $138(67.0)$ & $64(31.1)$ & $4(1.9)$ & \\
\hline 10 & Always wash hands with water and soap after cleaning a child's stool & $185(89.8)$ & $20(9.7)$ & $1(0.5)$ & \\
\hline 11 & Always wash hands with water and soap after cleaning duties & $168(81.6)$ & $34(16.5)$ & $4(1.9)$ & \\
\hline 12 & $\begin{array}{l}\text { Always wash hands with water and soap after picking something from } \\
\text { the floor }\end{array}$ & $147(71.4)$ & $54(26.2)$ & $5(2.4)$ & \\
\hline 13 & Always wash hands with water and soap after handling waste/garbage & $180(87.4)$ & $21(10.2)$ & $2(2.4)$ & \\
\hline 14 & Always wash hands with water and soap after touching animals & $153(74.2)$ & $44(21.4)$ & $9(4.4)$ & \\
\hline
\end{tabular}

Abbreviation: SD, standard deviation.

[AOR=0.06, (95\% CI: 0.01-0.25) $P<.001]$. Good hand hygiene practice at critical times was $99 \%$ lower among food handlers with negative attitudes towards hand as compared to food handlers with positive attitude $[\mathrm{AOR}=0.01$, $(95 \% \mathrm{CI}$ : $0.00-0.07) p<.001$ ] (Table 3).

Correlation between hand hygiene practices, attitudes and knowledge. Table 4 presents the correlation between hand hygiene practices, attitudes and knowledge. There was a strong positive correlation between attitude and practice $(r=0.839, P<.01)$, practice and knowledge $(\mathrm{r}=0.835, P<.01)$ and attitude and knowledge $(\mathrm{r}=0.766, P<.01)$.

Availability of hand bygiene facilities and practices of food handlers. The observational checklist revealed that the majority (72.8\%) of the food handlers did not have handwashing stations while only $41.7 \%$ of the food handlers had soap at their site of sale. About $29.1 \%$ of the food handlers handled food with bare hands, while $85.4 \%$ did not wash their hands after touching money. Proper handwashing was demonstrated by 


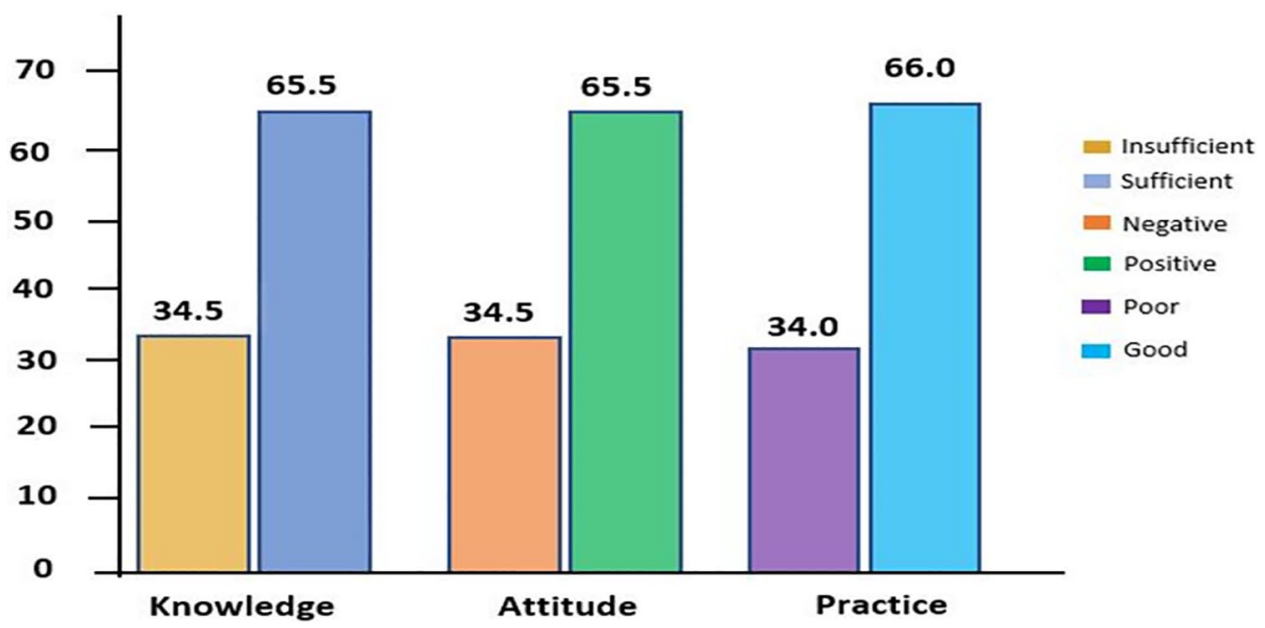

Figure 2. Knowledge, attitude and practices of food handlers regarding hand hygiene at critical times.

Table 3. Determinants of hand hygiene practice at critical times among educational institutions food handlers in the Sagnarigu Municipality.

\begin{tabular}{|c|c|c|c|c|c|c|c|}
\hline \multirow[t]{3}{*}{ VARIABLES } & \multirow[t]{3}{*}{ TOTAL (\%) } & \multicolumn{6}{|c|}{ HAND HYGIENE PRACTICE AT CRITICAL TIMES } \\
\hline & & \multicolumn{3}{|c|}{ CRUDE ODDS RATIO } & \multicolumn{3}{|c|}{ ADJUSTED ODDS RATIO } \\
\hline & & OR & $95 \% \mathrm{Cl}$ & $P$ VALUE & OR & $95 \% \mathrm{Cl}$ & $P$ VALUE \\
\hline \multicolumn{8}{|c|}{ Age group (years) } \\
\hline$<21$ & $12(5.8)$ & $\dagger$ & & & & & \\
\hline $21-30$ & $68(33)$ & 1.43 & $0.42-489$ & .570 & 0.08 & $0.00-1.69$ & .103 \\
\hline $31-40$ & $63(30.6)$ & 1.52 & $0.44-5.25$ & .508 & 0.02 & $0.00-0.48$ & .018 \\
\hline $41+$ & $63(30.6)$ & 4.73 & $1.28-17.44$ & .020 & 0.08 & $0.00-2.23$ & .138 \\
\hline \multicolumn{8}{|c|}{ Training on food safety } \\
\hline No & $52(25.2)$ & 0.05 & $0.02-0.12$ & $<.001$ & 0.04 & $0.00-0.41$ & .007 \\
\hline Yes & $154(74.8)$ & $\dagger$ & & & & & \\
\hline \multicolumn{8}{|c|}{ Receive education on handwashing } \\
\hline No & $42(20.4)$ & 0.08 & $0.03-0.18$ & $<.001$ & 1.95 & $0.15-25.05$ & .610 \\
\hline Yes & $164(79.6)$ & $t$ & & & & & \\
\hline \multicolumn{8}{|c|}{ Heard about handwashing at critical times } \\
\hline No & $48(23.3)$ & 0.02 & $0.01-0.07$ & $<.001$ & 0.20 & $0.03-1.57$ & .127 \\
\hline Yes & $158(76.7)$ & $\dagger$ & & & & & \\
\hline \multicolumn{8}{|c|}{ Knowledge of hand hygiene } \\
\hline Insufficient & $71(34.5)$ & 0.01 & $0.00-0.04$ & $<.001$ & 0.06 & $0.01-0.25$ & $<.001$ \\
\hline Sufficient & $135(65.5)$ & $t$ & & & $\dagger$ & & \\
\hline \multicolumn{8}{|c|}{ Attitude towards hand hygiene } \\
\hline Negative & $71(34.5)$ & 0.01 & $0.00-0.02$ & $<.001$ & 0.01 & $0.00-0.07$ & $<.001$ \\
\hline Positive & $135(65.5)$ & $\dagger$ & & & t & & \\
\hline
\end{tabular}

Abbreviation: $\mathrm{Cl}$, confidence interval.

Test statistically significant at $P<.05$; bold entries

tReference group. 
Table 4. Correlation between hand hygiene practices, attitude and knowledge toward hand hygiene at critical times.

\begin{tabular}{|llll|}
\hline VARIABLES & 1 & 2 & 3 \\
\hline 1. Practice & 1.000 & & \\
\hline 2. Attitude & $0.839^{\star}$ & 1.000 & \\
\hline 3. Knowledge & $0.835^{*}$ & $0.766^{*}$ & 1.000 \\
\hline
\end{tabular}

${ }^{*}$ Correlation is statistically significant at $P<.05$ (2 tailed).

only $17.0 \%$ of the study participants, with the majority $(83.0 \%)$ of them not using apron (Table 5).

\section{Discussion}

All the study participants in this study were females, which agrees with similar studies across the globe $11,32,41,42$ but differs from other studies that found males as the majority in food handling. ${ }^{43-46}$ Perhaps, the notion that the food handling business is the sole responsibility of females in Ghana may be the reason for female domination in this study. The minimum and maximum age of the study participants were 17 and 58, respectively, with most of them within the age group 20 to 30 years confirming the fact that food handling business belongs to younger and middle-aged women in Ghana. This is consistent with the literature in Ghana. ${ }^{17}$ Food handling, therefore, remains one of the primary sources of livelihood and income for young and middle-aged women in Ghana. Our findings revealed a significant number of food handlers receiving education on handwashing. Handwashing education is a critical component of changing behavior and improving handwashing practices in a population. ${ }^{47}$ Indeed, there is a direct relationship between education and good handwashing practice. ${ }^{17}$

A good number of the study participants had good hand hygiene practice at critical times. This is relatively consistent with a previous study among primary school food handlers in Malaysia $^{41}$ and mothers in Mandalay ${ }^{48}$ However, our finding relatively differs from surveys conducted among food handlers in Malaysia, ${ }^{49}$ women in Ethiopia ${ }^{40}$ and Indonesia. ${ }^{50}$ Differences in sociodemographic information, study population and settings may account for these differences in the practice of handwashing. It is, however, important to emphasize that self-reported hand hygiene practice does not necessarily translate into actual practice as people tend to over-report socially desirable behavior. ${ }^{51}$ Indeed, the observed data in this study revealed that only a few $(14.6 \%)$ of the food handlers wash their hands after the exchange of money between them and their consumers. In Ghana, Escherichia spp., Staphylococcus spp. and Salmonella spp. have been isolated from currency notes. Therefore, the concurrent handling of Ghana cedi notes with RTE food is a risk factor for cross-contamination of food. ${ }^{30}$ This can serve as a public health risk to patrons and consumers of RTE food in these educational institutions. ${ }^{52}$ The prevalence of handwashing after visiting the toilet was 96.6\%. This is consistent with similar studies in Nigeria (87.5\%). ${ }^{53}$ and
Table 5. Hand hygiene facilities and practices of the food handlers (observed).

\begin{tabular}{|c|c|c|}
\hline VARIABLES & $\begin{array}{l}\text { FREQUENCY, } \\
\mathrm{N}=206\end{array}$ & $\%$ \\
\hline \multicolumn{3}{|c|}{ Presence of handwashing station at food handler site } \\
\hline No & 150 & 72.8 \\
\hline Yes & 56 & 27.2 \\
\hline \multicolumn{3}{|c|}{ Presence of soap at food handler site } \\
\hline No & 120 & 58.3 \\
\hline Yes & 86 & 41.7 \\
\hline \multicolumn{3}{|c|}{ Condition of all fingernails } \\
\hline Not trimmed & 35 & 17.0 \\
\hline Trimmed & 171 & 83.0 \\
\hline \multicolumn{3}{|l|}{ Handling of food } \\
\hline Bare hands & 60 & 29.1 \\
\hline Use of gloves & 21 & 10.2 \\
\hline Use of ladle/spoon & 125 & 60.7 \\
\hline \multicolumn{3}{|c|}{ Hand washing after touching money } \\
\hline No & 176 & 85.4 \\
\hline Yes & 30 & 14.6 \\
\hline \multicolumn{3}{|c|}{ Use of clean water to wash hands } \\
\hline No & 94 & 45.6 \\
\hline Yes & 112 & 54.4 \\
\hline \multicolumn{3}{|c|}{ Food handler clothes are visibly neat } \\
\hline No & 25 & 12.1 \\
\hline Yes & 181 & 87.9 \\
\hline \multicolumn{3}{|c|}{ Jewellery is worn on hands } \\
\hline No & 170 & 82.5 \\
\hline Yes & 36 & 17.5 \\
\hline \multicolumn{3}{|c|}{ Food handler demonstrates proper handwashing technique } \\
\hline No & 171 & 83.0 \\
\hline Yes & 35 & 17.0 \\
\hline \multicolumn{3}{|l|}{ Use of hair protection } \\
\hline No & 6 & 2.9 \\
\hline Yes & 200 & 97.1 \\
\hline \multicolumn{3}{|c|}{ Food handler having apron on } \\
\hline No & 171 & 83.0 \\
\hline Yes & 35 & 17.0 \\
\hline
\end{tabular}

South-Western Ethiopia (77.0\%). ${ }^{54}$ Encouraging results were also reported by Ghartey and colleagues in Ghana (85.6\%). ${ }^{17}$ In Egypt, handwashing after toilet visits was relatively lower at $41.8 \% .^{55}$ Ignoring handwashing after toilet use is a significant risk factor for hand contamination. ${ }^{55}$ Indeed, the habit of not washing hands after toilet use is associated with higher positive cases of foodborne contaminants. ${ }^{53}$ 
In this study, a good number of the food handlers had training on food safety. This is in line with a previous study among food handlers in Malaysia ${ }^{14}$ but relatively higher than food safety training reported in other studies in Ethiopia ${ }^{54,56}$ and Egypt. ${ }^{55}$ Food safety training is crucial in improving the hygienic practices of food handlers. ${ }^{55,56}$ In this study, food handlers who had no food safety training were less likely to report good hand hygiene practices at critical times as compared to those with food safety training. This could be because food handlers might have received hand hygiene advice from relevant public health authorities during food safety training. In Ethiopia, the availability of service training on food safety was associated with good levels of food hygiene and safety measures. ${ }^{56}$

Food handlers' knowledge and attitudes towards hand hygiene were significantly associated with hand hygiene practices at critical times. Their knowledge of hand hygiene translated into hand hygiene practice; food handlers with insufficient knowledge were less likely to report good hand hygiene practice at critical times compared to those with sufficient knowledge of hand hygiene. In similar studies, food handlers' knowledge did not impact on strict hygienic practices. ${ }^{14,57}$ The finding of the present study, however, is consistent with that of Tan et al, who found a positive relationship between hand hygiene knowledge and self-reported hand hygiene practice. ${ }^{41}$ The influence of knowledge on reported hand hygiene practices may potentially impact the food handler's actual practice in food handling at work.

Food handlers with negative attitudes were 99\% less likely to self-report good hand hygiene practice compared to those with a positive attitude. Similar reports were also identified in other studies. ${ }^{49,58}$ Food safety interventions should seek to address gaps in food handlers' attitudes towards hand hygiene at critical times. In this study, there was a strong positive correlation between food handlers' hand hygiene attitudes and practices, practices and knowledge, and attitude and knowledge. These findings imply that food handlers' hand hygiene attitudes and knowledge significantly impact their practice. Positive correlations between food handlers' food safety knowledge, attitudes and practices have also been reported in previous studies. ${ }^{59,60}$ Another study in Saudi Arabia found positive correlations between knowledge, attitudes and personal hygiene. ${ }^{61}$ Evidence from this study suggests the need to strengthen food handlers' knowledge and attitudes to help improve food handlers' hand hygiene practice.

This study has limitations: the research could not establish a cause-effect relationship, which is inherent in cross-sectional designs, social desirability and recall bias are also some of the weaknesses of this study.

\section{Conclusion}

The results showed that the hand hygiene practice at critical times among the food handlers was relatively good and was independently predicted by food safety training, knowledge of hand hygiene and attitude towards hand hygiene. There was a significant positive correlation between food handlers' hand hygiene knowledge, attitude and practice. These findings underscore the vital role hand hygiene knowledge and attitude play in influencing food handlers' hand hygiene practice at critical times. Concerned stakeholders and organizations should, therefore, focus on WASH interventions that seek to improve educational institutions food handlers' knowledge and attitudes towards hand hygiene, coupled with training on food safety.

\section{Acknowledgement}

We are most grateful to the study participants, the educational institutions, the Sagnarigu Municipal Education Directorate and the data collectors.

\section{Authors' contribution}

SDD conceived and designed the study, developed the study tool, supervised the data collection and participated in interpreting the data and drafting of the manuscript, KEA did the data analysis and participated in interpreting the data and writing the manuscript, SKA participated in the study design and writing of the manuscript, LF participated in the data collection and writing of the manuscript, SA participated in the study design and writing of the manuscript, MEA participated in data analysis and writing and editing of the manuscript and HOA participated in the study design, study tool development and editing of the final paper. All authors read and approved the final manuscript.

\section{Availability of data and materials}

The data that support the findings of the research are available upon reasonable request from the corresponding author.

\section{Ethical approval and consent to participate}

Written informed consent was obtained from all study participants. Ethical approval for the study was obtained from the Committee on Human Research, Publication and Ethics of the Kwame Nkrumah University of Science and Technology.

\section{ORCID iDs}

Kingsley E Amegah (iD https://orcid.org/0000-0002-5251-1166

Henry O Addo (iD https://orcid.org/0000-0002-4773-5632

S Dajan Dubik iD https://orcid.org/0000-0001-9833-2676

\section{REFERENCES}

1. World Health Organization. WHO estimates of the global burden of foodborne diseases: foodborne disease burden epidemiology reference group 2007-2015. Geneva, Switzerland: World Health Organization; 2015.

2. Jaffee S, Henson S, Unnevehr L, Grace D, Cassou E. The safe food imperative: accelerating progress in low-and middle-income countries. Washington, DC: The World Bank; 2018.

3. Havelaar AH, Kirk MD, Torgerson PR, et al. World Health Organization global estimates and regional comparisons of the burden of foodborne disease in 2010. PLoS Med. 2015;12:e1001923.

4. Graphic online. Unsafe food costs Ghana US\$69 million annually, 2015. https:// www.graphic.com.gh/news/general-news/unsafe-food-costs-ghana-us-69-million-annually.html

5. Yeleliere E, Cobbina SJ, Abubakari ZI. Review of microbial food contamination and food hygiene in selected capital cities of Ghana. Cogent Food Agric. 2017;3:1395102. 
6. Saba CK, Gonzalez-Zorn B. Microbial food safety in Ghana: a meta-analysis. J Infect Dev Ctries. 2012;6:828-835.

7. Ofosu AH, Dzigbede BA, Agidi JE, Adjei J, Koranteng A. A study into microbial quality of ready to eat foods sold in the Sunyani Municipality of Ghana. Glob J Biol Agri Health Sci. 2014;3:84-91.

8. Ingelfinger JR. Melamine and the global implications of food contamination. $N$ Engl J Med. 2008;359:2745-2748.

9. World Health Organization. Food safety; 2019. https://www.who.int/en/newsroom/fact-sheets/detail/food-safety. Accessed January 5, 2020.

10. World Health Organization. Regional Office for Africa "Developing and Maintaining Food Safety Control Systems for Africa Current Status and Prospects for Change", Second FAO/WHO Global Forum of Food Safety Regulators. Bangkok, Thailand; 2004: 12-14. http://www.fao.org/3/ae144e/ae144e00.htm. Accessed January 5, 2020

11. Monney I, Agyei D, Owusu W. Hygienic practices among food vendors in educational institutions in Ghana: the case of Konongo. Foods. 2013;2:282-294.

12. Michaels B, Keller C, Blevins M, et al. Prevention of food worker transmission of foodborne pathogens: risk assessment and evaluation of effective hygiene intervention strategies. Food Serv Technol. 2004;4:31-49.

13. Hadir EK. Efficacy of different alcohol-based hand disinfectants in reduction of hand contamination among food handlers in Alexandria, Egypt. J Adv Microbiol. 2018;16:1-3.

14. Lee HK, Abdul Halim H, Thong KL, Chai LC. Assessment of food safety knowledge, attitude, self-reported practices, and microbiological hand hygiene of food handlers. Int J Environ Res Public Health. 2017;14:55.

15. Honua MH. The bacterial contamination of food handlers hands in Wad madani city restaurants, Sudan. Int J Community Med Public Health. 2018;5:1270.

16. Rosmawati NH, Manan WM, Izani NJ, Nurain NH. Evaluation of environmental hygiene and microbiological status of selected primary school canteens. $J$ Health Environ. 2014;5:110-127.

17. Ghartey Af, Antwi Bk. Hand hygiene practices among street food vendors. Food Environ SafJ. 2019;18(2).

18. Kariuki EN, Waithera NZ, Wanzala P. Bacteriological contamination of street foods among street food vendors in githurai and gikomba markets-Nairobi county, Kenya. Int J Innov Res Adv Stud. 2017;4:337-346.

19. Center for Disease Control and Prevention. When and how to wash your hands. https://www.cdc.gov/handwashing/when-how-handwashing.html\#: :text =Follow $\% 20$ these $\% 20$ five $\% 20$ steps $\% 20$ every,for $\% 20$ at $\% 201$ east $\% 2020 \% 20$ second

20. Scott BE, Lawson DW, Curtis V. Hard to handle: understanding mothers' handwashing behaviour in Ghana. Health Policy Plan. 2007;22:216-224.

21. World Health Organization. Five Keys to Safer Food Manual. WHO Department of Food Safety, Zoonoses and Foodborne Diseases. Geneva, Switzerland: WHO; 2006.

22. Ameme DK, Alomatu H, Antobre-Boateng A, et al. Outbreak of foodborne gastroenteritis in a senior high school in South-eastern Ghana: a retrospective cohort study. BMC Public Health. 2016;16:564.

23. Opare JK, Afari E, Wurapa F, et al. Gastroenteritis Outbreak in a Senior High School, Akwapim North District, Eastern Region-Ghana; 2012. https://imsear. searo.who.int/handle/123456789/153250

24. Ghanaweb. Scores of Accra High School students hospitalized over suspected food poisoning, 2019. https://www.ghanaweb.com/GhanaHomePage/NewsArchive/Scores-of-Accra-High-School-students-hospitalized-over-suspected -food-poisoning-805444

25. Ghnewsonline.com. University of Cape Coast close down all food joints on campus, 2014. http://ghnewsonline.com/2014/09/ucc-close-down-all-food-joints-on -campus/

26. Malm KL, Nyarko KM, Yawson AE, Gogo B, Lawson A, Afari E. Foodborne illness among school children in Ga East, Accra. Ghana Med J. 2015;49: 72-76.

27. Ameme DK, Abdulai M, Adjei EY, et al. Foodborne disease outbreak in a resource-limited setting: a tale of missed opportunities and implications for response. Pan Afr Med J. 2016;23.

28. Esena RK, Owusu E. Quality of cooked foods in urban schools in Ghana: review of food borne diseases and health implications. Int J Sci Technol Res. 2013;2:267-275.

29. Angelakis E, Azhar EI, Bibi F, et al. Paper money and coins as potential vectors of transmissible disease. Future Microbiol. 2014;9:249-261.

30. Luure P, Asare W, Cobbina SJ, Duwiejuah AB, Nkoom M. Microbial contamination of Ghanaian cedi notes from traders of the tamale central market, Ghana. Microbiol Res J Int. 2015:139-145.

31. Ntow GE, Kwabla MP, Der J. Hygiene practices among food vendors in Hohoe Township. Cent Afr J Public Health. 2016;2:43-50.

32. Monney I, Agyei D, Ewoenam BS, Priscilla C, Nyaw S. Food hygiene and safety practices among street food vendors: an assessment of compliance, institutional and legislative framework in Ghana. Food Public Health. 2014;4:306-315.

33. Odonkor ST, Adom T, Boatin R, Bansa D, Odonkor CJ. Evaluation of hygiene practices among street food vendors in Accra metropolis, Ghana. Elixir Online J. 2011;41:5807-5811.

34. Wuliyeng GT. Examining the Hygiene Practices among Street Food Vendors in Nsawam and Adoagyiri [Master dissertation]. University of Ghana; 2013. http://ugspace. ug.edu.gh/handle/123456789/8147\#: :text=It\%20was\%20found\%20that $\% 20$ poor,same $\% 20$ hands $\% 20$ to\%20receive $\% 20$ money.
35. Dajaan DS, Addo HO, Luke O, Eugenia A, Amshawu A, Kwasi NA. Food hygiene awareness and environmental practices among food vendors in basic schools at Kintampo township, Ghana. Food Public Health. 2018;8:13-20.

36. Addison IE. Hygienic Practices among Food Vendors in the University of Ghana [Masters dissertation]. University of Ghana; 2015. http://ugspace.ug.edu.gh/ handle/123456789/8180

37. GSS. Sagnarigu District analytical report. 2010 Population and Housing Census, 2014. http://www2.statsghana.gov.gh/docfiles/2010_District_Report/ Northern/Sagnarigu.pdf

38. Sagnerigu District Assembly. Composite budget for 2018-2021 program based budget estimates for 2018. https://www.mofep.gov.gh/sites/default/files/composite-budget/2018/nr/sagnarigu.pdf

39. Cochran WG. Sampling Techniques. 2nd ed. New York: John Wiley and Sons, Inc.; 1963.

40. Dagne H, Bogale L, Borcha M, Tesfaye A, Dagnew B. Hand washing practice at critical times and its associated factors among mothers of under five children in Debark town, northwest Ethiopia, 2018. Ital J Pediatr. 2019;45:120.

41. Tan SL, Bakar FA, Karim MS, Lee HY, Mahyudin NA. Hand hygiene knowledge, attitudes and practices among food handlers at primary schools in Hulu Langat district, Selangor (Malaysia). Food Control. 2013;34:428-435.

42. Samapundo S, Climat R, Xhaferi R, Devlieghere F. Food safety knowledge, attitudes and practices of street food vendors and consumers in Port-au-Prince, Haiti. Food Control. 2015;50:457-466.

43. Donkor ES, Kayang BB, Quaye J, Akyeh ML. Application of the WHO keys of safer food to improve food handling practices of food vendors in a poor resource community in Ghana. Int J Environ Res Public Health. 2009;6:2833-2842.

44. Choudhury M, Mahanta L, Goswami J, Mazumder M, Pegoo B. Socio-economic profile and food safety knowledge and practice of street food vendors in the city of Guwahati, Assam, India. Food Control. 2011;22:196-203.

45. Muinde OK, Kuria E. Hygienic and sanitary practices of vendors of street foods in Nairobi, Kenya. Afr J Food Agri Nutr Dev. 2005;5(1).

46. Ma L, Chen H, Yan H, Wu L, Zhang W. Food safety knowledge, attitudes, and behavior of street food vendors and consumers in Handan, a third tier city in China. BMC Public Health. 2019;19:1128.

47. Cortese RD, Veiros MB, Feldman C, Cavalli SB. Food safety and hygiene practices of vendors during the chain of street food production in Florianopolis, Brazil: a cross-sectional study. Food Control. 2016;62:178-186.

48. Oo WM, Hlaing HH, Aung HL. Proper hand washing practice among mothers and occurrence of diarrhoea among family members. Burma Med J. 2014;56:9-14.

49. Rahman MM, Arif MT, Bakar K, bt Talib Z. Food safety knowledge, attitude and hygiene practices among the street food vendors in Northern Kuching City, Sarawak. Borneo Sci. 2016. https://jurcon.ums.edu.my/ojums/index.php/borneoscience/article/view/169

50. Firdaus MS, Arya IF, Somasetia DH. Mothers' hand washing practice and diarrhea cases in children under five in Baleendah, Bandung. Althea Med J. 2015;2:191-198.

51. Contzen N, De Pasquale S, Mosler HJ. Over-reporting in handwashing selfreports: potential explanatory factors and alternative measurements. PLoS One. 2015;10:e136445.

52. Michaels B. Handling money and serving ready-to-eat food. Food Serv Technol. 2002;2:1-3.

53. Zaglool DA, Khodari YA, Othman RA, Farooq MU. Prevalence of intestinal parasites and bacteria among food handlers in a tertiary care hospital. Niger Med J. 2011;52:266-270.

54. Assefa T, Tasew H, Wondafrash B, Beker J. Assessment of bacterial hand contamination and associated factors among food handlers working in the student cafeterias of Jimma University Main Campus, Jimma, South West Ethiopia. Community Med Health Educ. 2015;5:1000345.

55. Allam HK, Al-Batanony MA, Seif AS, Awad ET. Hand contamination among food handlers. Microbiol Res J Int. 2016;14:1-8.

56. Adane M, Teka B, Gismu Y, Halefom G, Ademe M. Food hygiene and safety measures among food handlers in street food shops and food establishments of Dessie town, Ethiopia: a community-based cross-sectional study. PLoS One. 2018;13:e0196919.

57. Akabanda F, Hlortsi EH, Owusu-Kwarteng J. Food safety knowledge, attitudes and practices of institutional food-handlers in Ghana. BMC Public Health. 2017;17:40.

58. Abdul-Mutalib NA, Abdul-Rashid MF, Mustafa S, Amin-Nordin S, Hamat RA, Osman M. Knowledge, attitude and practices regarding food hygiene and sanitation of food handlers in Kuala Pilah, Malaysia. Food Control. 2012;27:289-293.

59. Asmawi UM, Norehan AA, Salikin K, Rosdi NA, Munir NA, Basri NB. An assessment of knowledge, attitudes and practices in food safety among food handlers engaged in food courts. Curr Res Nutr Food Sci J. 2018;6:346-353.

60. Ncube F, Kanda A, Chijokwe M, Mabaya G, Nyamugure T. Food safety knowledge, attitudes and practices of restaurant food handlers in a lower-middleincome country. Food Sci Nutr. 2020;8:1677-1687.

61. Al-Shabib NA, Mosilhey SH, Husain FM. Cross-sectional study on food safety knowledge, attitude and practices of male food handlers employed in restaurants of King Saud University, Saudi Arabia. Food Control. 2016;59:212-217. 


\section{Figures}

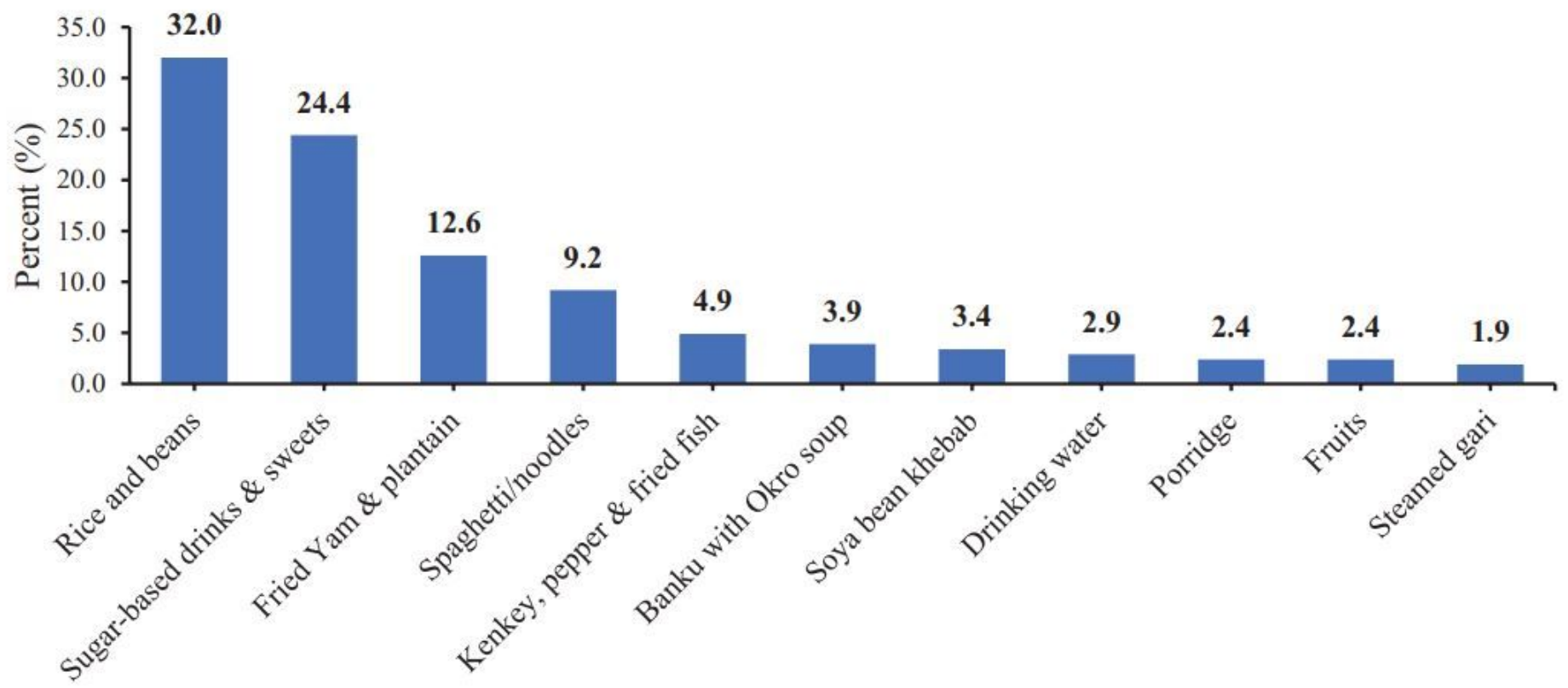

Figure 1

Foods sold by food handlers at the various schools.

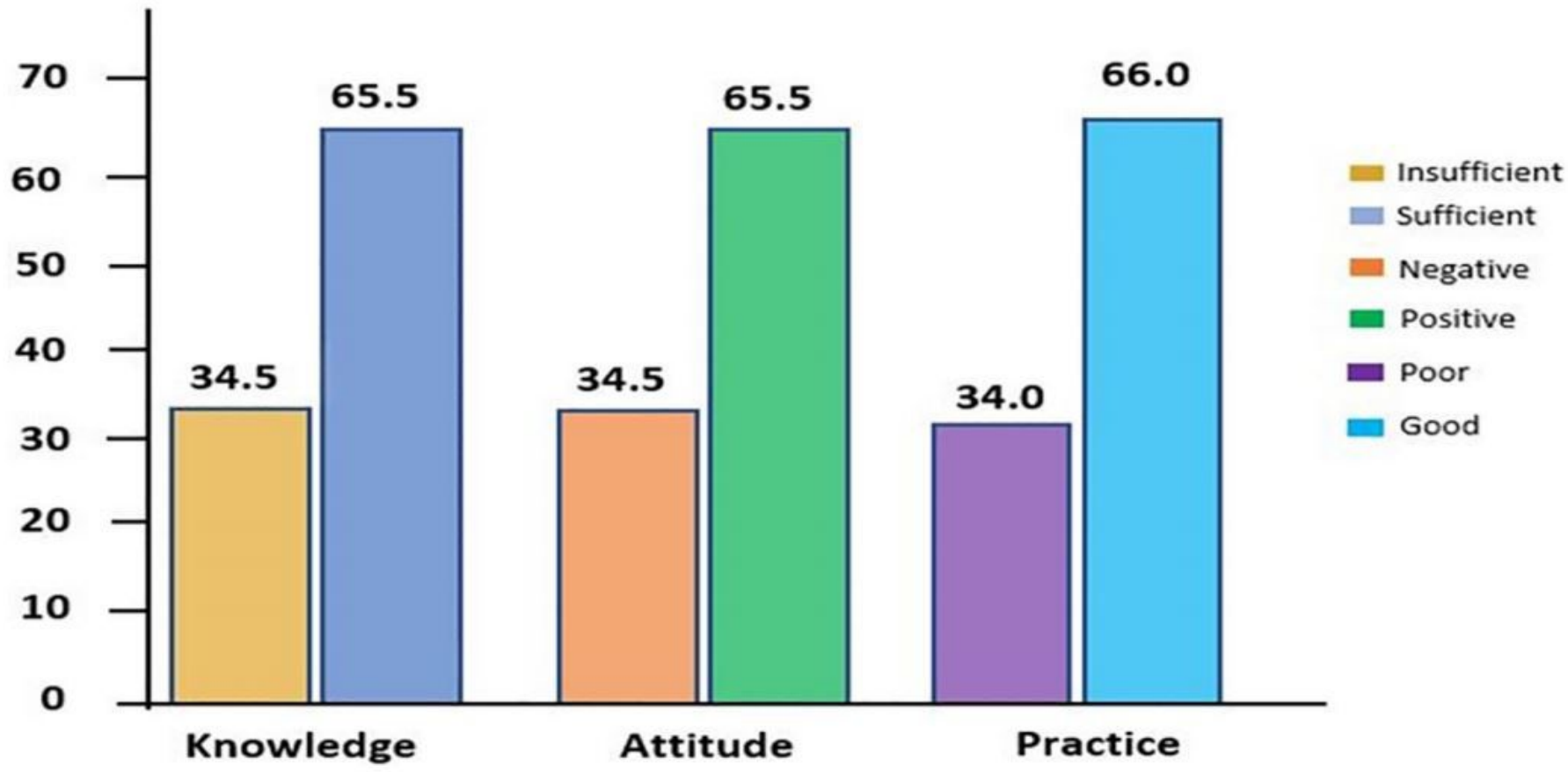

Figure 2

Knowledge, attitude and practices of food handlers regarding hand hygiene at critical times. 